\title{
ADMINISTRAÇÃO E GESTÃO DE DOCUMENTOS NA ESCOLA MUNICIPAL AMAZONAS
}

\section{ARTIGO ORIGINAL}

SILVA, Isabelle Quixaba da ${ }^{1}$

MELO, Jéssica Karen Souza de ${ }^{2}$

ARAUJO, Israel De Carvalho Drumond ${ }^{3}$

SILVA, Isabelle Quixaba da. MELO, Jéssica Karen Souza de. ARAUJO, Israel De Carvalho Drumond. Administração e gestão de documentos na Escola Municipal Amazonas. Revista Científica Multidisciplinar Núcleo do Conhecimento. Ano 05, Ed. 11, Vol. 20, pp. 64-81. Novembro de 2020. ISSN: 2448-0959, Link de acesso:https://www.nucleodoconhecimento.com.br/administracao/municipal-

\section{amazonas}

\section{RESUMO}

O presente artigo tem como objetivo analisar e trabalhar a problemática da gestão de documentos nos dias atuais, considerando os desafios encontrados e pensando em como tal método poderia ser efetivo em instituições que lidam com alto fluxo de documentos e informações importantes, como é o caso das unidades escolares. A discussão relaciona-se com o papel da Administração Escolar, abordando sua importância para alcançar os objetivos reais e diários da organização. Como objeto de estudo, adotou-se a secretaria da Escola Municipal Amazonas, localizada no bairro de Campo Grande, Zona Oeste da cidade do Rio de Janeiro. E a metodologia utilizada envolveu o estudo de caso, com observação da rotina dos profissionais e entrevistas

\footnotetext{
${ }^{1}$ Bacharelanda em Administração Pública.

2 Bacharelanda em Administração Pública.

3 Orientador. Graduação em Ciências Contábeis. Graduação em Administração Pública.
} 
com os mesmos. Os resultados obtidos envolvem a comprovação da falta de recursos e investimentos nos procedimentos que possibilitam a gestão de documentos, além da baixa capacitação dos profissionais para a realização da gestão digital de documentos.

Palavras-chave: Administração Escolar, gestão de documentos, Escola Municipal.

\section{INTRODUÇÃO}

Atualmente a sociedade está cada vez mais ciente da escassez de recursos materiais e financeiros. E como a sociedade passa pela quarta revolução industrial e por uma gestão ambiental que preza pela sustentabilidade, torna-se comum o racionamento de plástico e papel. Este último, no entanto, faz parte e possui grande destaque na gestão pública, pois aparece principalmente em arquivos e na forma documentos. $\mathrm{O}$ que torna seu racionamento difícil e de complicado desapego pelos funcionários.

Neste relatório é abordada a gestão de arquivos e documentos da secretaria escolar da Escola Municipal Amazonas. Sendo escolhida, por ser o setor que gera e repassa o maior volume de documentos e informações desta instituição, além de ser o ponto central de toda a escola na perspectiva de comunicação. Que conta com o apoio de uma equipe de profissionais com variadas funções e responsabilidades, que colaboram para o andamento, não apenas das demandas internas, como também externas do ambiente escolar.

Na perspectiva interna estão: os fluxo de documentos (atas, histórico escolar, boletim, etc), atendimento à comunidade escolar (alunos, responsáveis, profissionais internos), contribuindo assim diretamente no bom funcionamento da administração escolar. Assim, no que se refere às demandas externas, é possível citar além do relacionamento com o público (vizinhança, fornecedores, etc), a prestação de contas aos órgãos superiores (Coordenadoria Regional de Educação - CRE, Secretaria Municipal de Educação - SME, etc).

A seguinte pesquisa visa, portanto, analisar utilizando não somente, a ferramenta da observação da rotina, mas também com o auxílio do posicionamento do corpo de 
profissionais que compõem a secretária, visando entender os pontos da real necessidade e dos desafios para tornar concreto o objetivo da gestão de digitalização de documentos.

\section{APRESENTAÇÃO DO CASO}

A Escola Municipal Amazonas foi construída em 1941 pela prefeitura do Distrito Federal, sob mandato do Presidente Getúlio Vargas. Localizada no bairro de Campo Grande na Zona Oeste do Rio de Janeiro, a unidade escolar é bem favorecida contando com pontos de ônibus de acesso rápido possibilitando dinamismo na locomoção aos bairros e sub-bairros da redondeza. Devido à proximidade da Rodovia Luiz Henrique Rezende Novaes/Antiga Estrada Rio São Paulo, a perspectiva de facilidade de acesso é ampliada ao público de outros municípios, como Seropédica, Nilópolis e Nova Iguaçu.

Imagem 1: Fotografia da placa de fundação da Escola Municipal Amazonas 


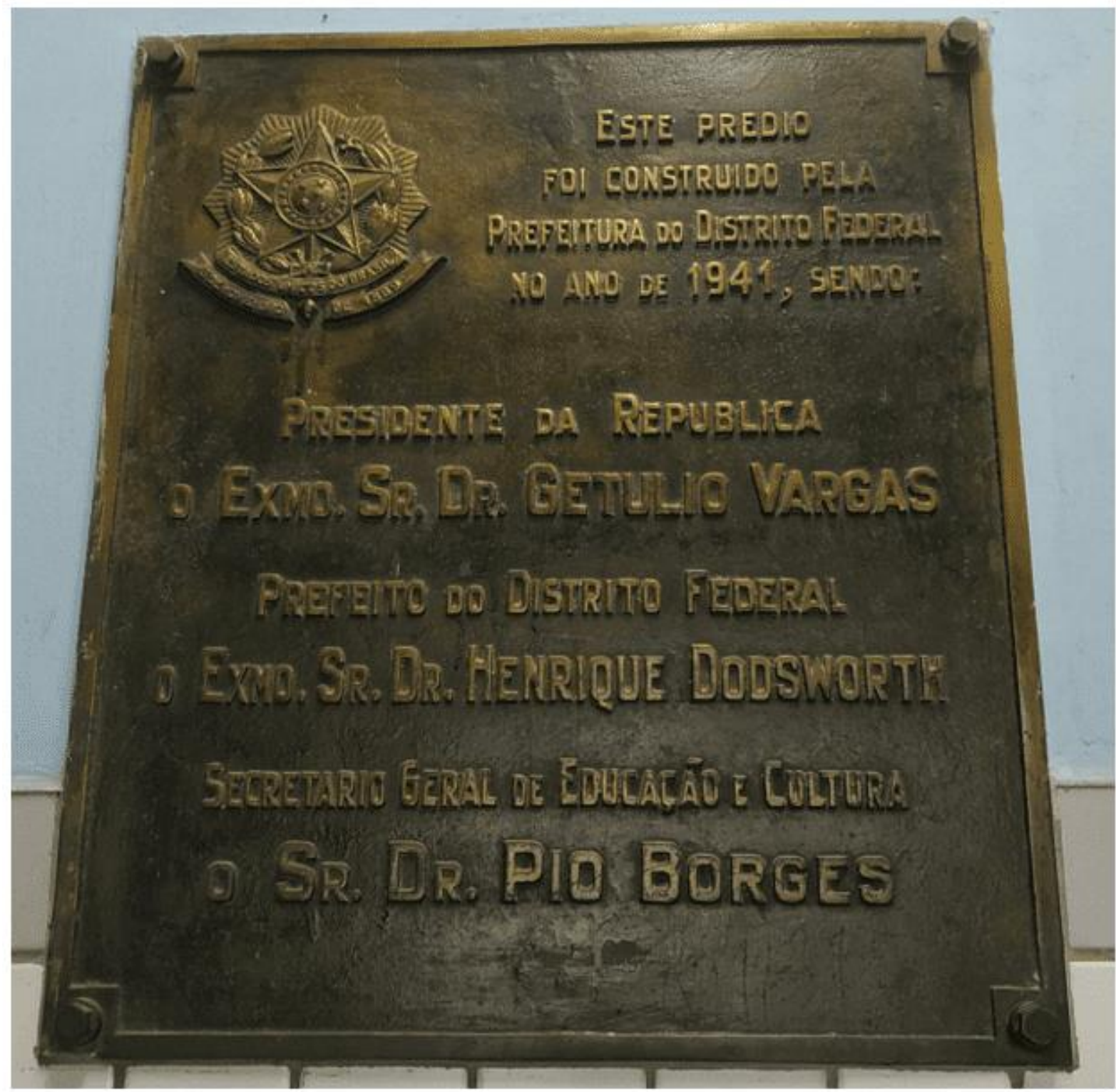

Fonte: Elaborado pelo autor.

A escola atualmente conta com um corpo de funcionários de aproximadamente 60 profissionais, entre professores, coordenadores, secretários, diretores (entre outros), que colaboram com suas funções e responsabilidades para o andamento de todas as tarefas. Além disso, o número total de alunos varia durante todo o ano, entre 550 a 600 estudantes, pelo motivo da ocorrência de entradas (matrículas) e saídas (transferências). O período das atividades do ano letivo é dividido em quatro bimestres, podendo o aluno cursar no primeiro turno (de 7h30min às $12 \mathrm{~h}$ ), ou no 
horário da tarde (de 12h50min às 17h). A Escola Municipal Amazonas faz parte das 220 unidades exclusivas ${ }^{[4]}$ de Ensino Fundamental II do município do Rio de Janeiro.Fonte: Elaborado pelo autor.

A unidade não possui uma gestão de arquivos e documentos totalmente digitalizada, o que acaba favorecendo o retrabalho e consequentemente uma diminuição de produtividade por parte da secretaria que é a principal alimentadora de dados do sistema eletrônico vigente atualmente na escola.

$\mathrm{O}$ arquivo permanente fica no $2^{\circ}$ (segundo) andar da unidade escolar, onde está programada uma reforma para melhorar o layout de armazenamento. Entretanto o mesmo necessita de uma nova classificação de documentos, pois com o passar dos anos a gestão de documentos passou por diversas transformações. O que deixou o antigo sistema obsoleto e de difícil entendimento.

\section{REFERENCIAL TEÓRICO}

\subsection{A ADMINISTRAÇÃO X GESTÃO ESCOLAR}

$\mathrm{Na}$ administração, seja no meio público ou privado, é possível identificar através de conversas, conteúdos físicos, como livros e artigos, por um lado a menção da palavra "gestão" e por outro da "administração", referindo-se à um mesmo significado, ou em definições distintas. Com o objetivo de evitar a dualidade de ideias, segue as seguintes definições de administração e gestão, respectivamente:

Administração:

1 Ato, processo ou resultado de administrar.

2 Ato de governar, dirigir ou gerir; governo, direção, gerência [...].

3 Conjunto de princípios, práticas e técnicas utilizadas com o objetivo de coordenar e dirigir as ações de um grupo de indivíduos que se associam com o fim de conseguir resultados eficazes. (Dicionário Michaelis Online, grifo nosso). 
Assim, é possível observar que a administração se liga diretamente às técnicas para somente deste modo aplicar as ações. Seguindo as definições, encontra-se ainda: "Gestão: Ato de gerir ou administrar [...]". (Dicionário Michaelis Online). Comparando com a definição anterior, a palavra gestão foi totalmente dessemelhante pela perspectiva da qualidade da informação.

Com base nisso, faz-se necessário o aprofundamento teórico, utilizando o auxílio de autores como Amaral e Nunes (2017) que dedicam um capítulo de seu artigo para abordar de forma conceitual as relações entre gestão, administração e gestão administrativa. A baixa frequência de discussões relacionadas à esses termos vêm ocasionando ou a menção aleatória, considerando ambas como o mesmo, ou a consequente limitação, como mencionado pelos autores: "em sua análise, [dispõe] gestão como mais apropriado para ação sobre o bem privado, e administração, o correto sobre o bem público". (apud DIAS, 2002).

Nesse sentido, Amaral e Nunes (2017) utilizam o trabalho de Santos, Santos e Braga (2014, apud CUNHA, 2000), para uma abordagem com caráter conclusivo em que a ciência organizacional é entendida como um dos domínios disciplinares que ajudam a formar o território multidisciplinar que é a gestão. Ou seja, nem tudo o que é gestão é do domínio da ciência organizacional, mas toda ciência organizacional pode ser entendida como podendo ser abarcada por uma ciência de gestão que demonstra preocupações não apenas aplicadas, como também, teóricas.

Estabelecido esse ponto de partida, pode-se considerar que a administração alia a carga teórica e sua aplicação, tendo como base princípios, utilizando ferramentas de planejamento e controle a fim de alcançar o objetivo da organização. No meio escolar, essa definição aplica-se de igual forma. Para entender os princípios de organização e administração escolar, a partir desse momento será utilizado como embasamento principal a Coleção Lourenço Filho 8 que aborda a temática administrativa relativa ao contexto educacional.

É possível afirmar que as escolas são organizações que precisam do apoio administrativo tendo em vista que "[...] cada uma terá de atender a objetivos gerais e 
comuns a todas as escolas, que são os de oferecer oportunidades para o desenvolvimento individual dos alunos." (LOURENÇO FILHO, 2007, p.25). As ações tomadas pelos indivíduos competentes (ou não), sempre gerarão consequências àqueles que compõem a organização. No caso da escola isso não é diferente, a comunidade escolar formada por: colaboradores, pais e responsáveis, alunos e vizinhança, estão diretamente ligados às práticas mencionadas, ainda que em níveis diferentes.

\subsection{GESTÃO DE DOCUMENTOS E ARQUIVOS}

No dicionário documento é definido como: "título ou diploma que serve de prova: documento histórico"/“Qualquer objeto ou fato que serve de prova, confirmação ou testemunho: documentos fotográficos". Já o arquivo, é definido como: "acumulação ordenada dos documentos [...], criados por uma instituição ou pessoa, no curso de sua atividade, e preservados para a consecução de seus objetivos, visando à utilidade que poderão oferecer no futuro". (PAES, 2004, p.16)

Convém mencionar que no Brasil, a Lei no 8.159, de 08 de janeiro de 1991. Versa sobre a política nacional de arquivos públicos e privados, que no artigo 1ำ do Capítulo I da lei, declara que é dever do Poder Público a gestão documental e a proteção especial a documentos de arquivos. Onde também coloca a gestão e proteção documental como instrumento de apoio administrativo.

Dito isso, no Capítulo II, define o que se entende por arquivo público. Declarando no artigo $7^{\circ}$, como: "conjunto de documentos produzidos e recebidos, no exercício de suas atividades, por órgãos públicos de âmbito Federal, estadual, do Distrito Federal e municipal em decorrência de suas funções administrativas, legislativas e judiciárias"(1991). Esses documentos públicos são identificados em três categorias: correntes, intermediários e permanentes. Essa classificação se dá pelo uso, movimentações e consultas feitas por razões de interesse administrativo. Entre outras palavras, isso quer dizer que quanto mais o documento for consultado ou movimentado mais corrente, ele será. 
A Escola Municipal Amazonas apresenta a peculiaridade de possuir esses três tipos de documentos arquivados em sua Unidade Escolar, pois como já citado anteriormente é uma escola de 79 anos de existência. Inclusive possui duas formas de arquivamento, um acervo físico em papel e outro por meio digital, este último no formato de documento digital e formulário eletrônico. Onde o documento digital fica armazenado nos computadores locais e o formulário eletrônico é fornecido pela própria Secretaria de Educação Municipal por meio de endereço eletrônico próprio, formando um banco de dados online.

Assim é perceptível que:

o registro da vida escolar dos alunos e os boletins escolares - documento para comunicação entre a escola e os pais, no que se refere ao aproveitamento do aluno -, têm se alterado muito nos últimos anos. Estas alterações decorrem das concepções de avaliação, do significado da comunicação entre a escola e os pais, do seu suporte e tecnologia, bem como dos projetos institucionais e seu contexto. [...] o boletim escolar está sendo disponibilizado na página web das escolas; como documento digital [...]. (WERLE, 2002, p. 78).

Esta citação é verdadeira, pois quando há um pedido de histórico escolar de algum aluno da década de 60 na Unidade Escolar, por exemplo, os conceitos de avaliação dos alunos são nitidamente diferentes dos utilizados atualmente. Além disso, hoje os boletins escolares podem ser acessados no endereço eletrônico da própria Prefeitura do Município do Rio de Janeiro.

Dando continuidade a comparação dos boletins escolares do passado e do presente, informando a respeito de suas confecções, observa-se que:

No caso do boletim eletrônico as informações têm sua origem na forma digital uma vez que estão contidas num banco de dados informatizado. O conjunto de registros que compõe esse banco de dados pode dar origem a informações obtidas mediante a aplicação de "filtros seletivos" que as organizam sinteticamente de diferentes formas, seja na aparência de boletim com as notas de um aluno específico, seja na forma de gráficos e índices, por turma, por componente curricular, e outras combinações as quais, individualmente, podem constituir documentos. Ao contrário, no caso do boletim impresso em cartolina, cada um deles 
era confeccionado individualmente, a partir de outros documentos como cadernos de chamada e atas de aproveitamento. (WERLE, 2002, p. 78).

No caso da Escola Municipal aqui analisada, não ocorreu a total migração para o sistema digital. Aqui é importante frisar que a sociedade está em constante evolução tecnológica e que são os documentos intermediários e permanentes da unidade que estão em processo de digitalização, entretanto uma escola pública não terá um avanço tecnológico igual ou superior a de uma escola particular. A alimentação de dados no sistema de arquivos é feita por processo manual, que consiste em um ou vários colaboradores dando entrada em dados, documentos e arquivos para a instituição. Esse fato é relevante, porque foram observadas muitas informações em formulários eletrônicos que alimentam o Banco de Dados da Secretaria Municipal preenchidos de maneira equivocada, assim o retrabalho também é constituído por erro humano e demonstra quão importante é uma equipe bem instruída e preparada.

Em relação aos avanços digitais, Werle (2002) também comenta que quanto maior o nível tecnológico a escola possui, maior é o distanciamento do corpo administrativo com os alunos e responsáveis. Aqui é um pouco difícil especular, mas o que foi observado na atual gestão da unidade é do grande esforço da parte do corpo administrativo de estar constantemente disponível para atender as demandas da comunidade em seu entorno. Um dos comentários feitos por funcionários antigos, é que houve uma melhora na participação dos pais no ambiente escolar com essa nova gestão.

Logo, poderia se concluir que uma gestão participativa diminui a distância imposta pela tecnologia. Por conseguinte, a necessidade de gerenciar os documentos produzidos pelas unidades escolares, gera um processo de tomada de decisão. Pois as instituições devem saber o que manter e como manter os documentos por elas produzidos, no entanto a gestão de arquivos não é uma ciência exata e o que era armazenado no passado, num futuro próximo pode vir a ser considerado irrelevante. Isso acaba por provocar uma incerteza em diversas organizações, pois as mesmas ficam sem saber o que fazer com determinados arquivos. Principalmente as instituições públicas, pois por elas passam muitos documentos transversais. A 
frequência escolar no Brasil, por exemplo, é requisito para recebimento de renda financeira oriunda do Programa Bolsa Família e pode inclusive ser um dado requisitado num processo judicial da Vara da Infância e Juventude ou na Vara da Família.

\section{PLANO dE AÇÃO}

\subsection{DIAGNÓSTICO ORGANIZACIONAL}

Para determinar o setor escolhido para esse trabalho, foi utilizado entrevistas e uma pesquisa de levantamento de dados. Desse modo o setor da Escola Municipal Amazonas mais relevante para a construção desse artigo foi a secretaria escolar.

Optou-se então, por utilizar o Diagrama de Causa e Efeito para determinar a relação entre um efeito e suas possíveis causas. Que nesse caso o efeito foi o Arquivo Geral da Instituição (arquivo, documentos em papel e digitais) e as causas da sua falta de eficiência foram listadas utilizando a metodologia 6M's.

Imagem 2: Diagrama de Causa e Efeito do Arquivo Geral

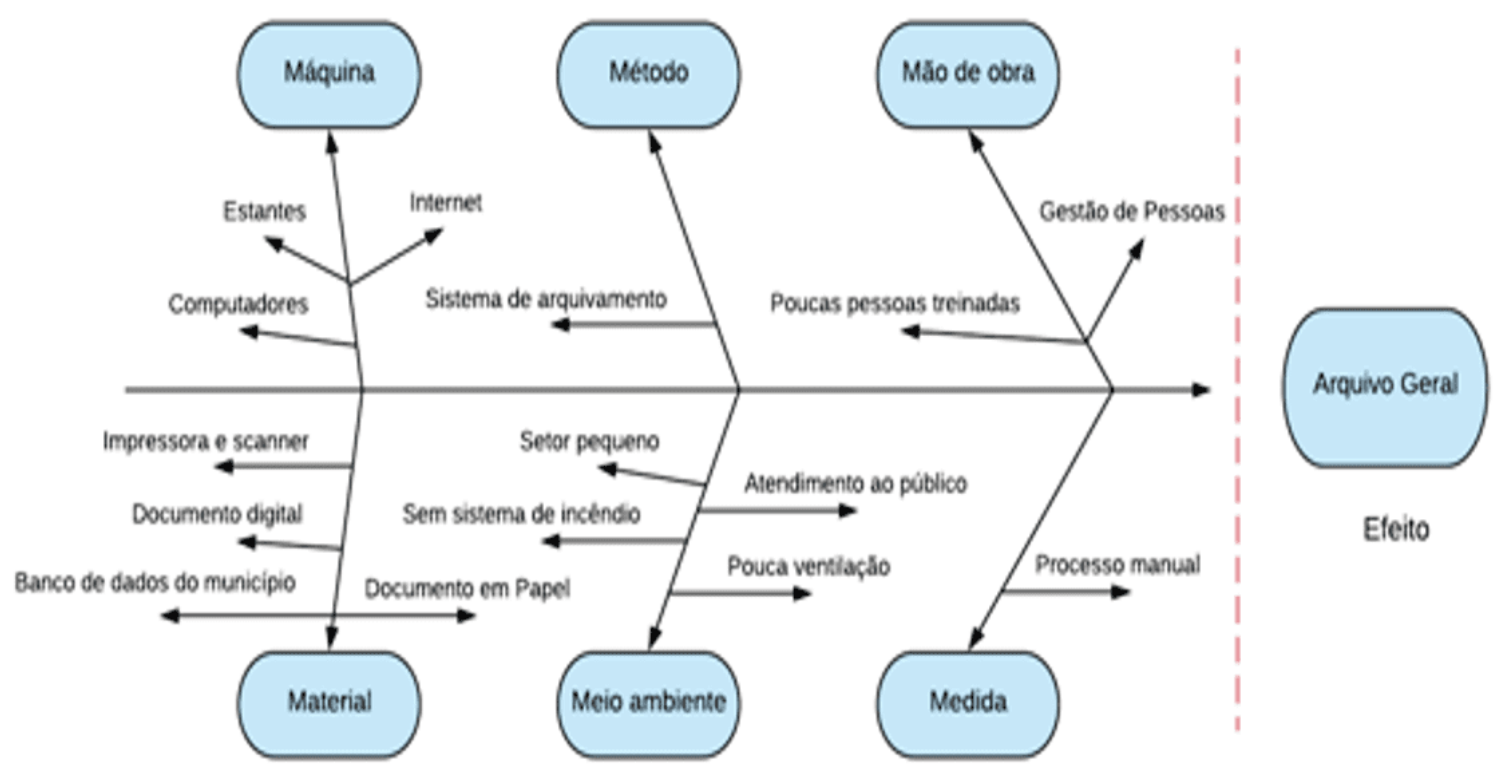

Fonte: Elaborado pelo autor. 
Trabalha-se com as causas de Gestão de Pessoas e Gestão de Arquivos e Documentos, porque embora sejam temáticas distintas, são co dependentes, pois um depende do outro para exercer seu papel na Organização. Para demonstrar que as causas escolhidas se relacionam, utiliza-se a Teoria dos dois fatores de Frederick Herzberg ${ }^{[5]}$ com a finalidade de melhor explicação e entendimento sobre o tema demonstrado.

As Gestões de Pessoas, Arquivos e Documentos são fatores higiênicos de responsabilidade da Organização, onde o tratamento das mudanças está mais no foco de geração de políticas e normas organizacionais. São áreas de tremenda importância na geração de Tomada de Decisão e impactam grandemente na Gestão Pública Brasileira.

O arquivamento escolar deve seguir um método e um sistema previamente definido pela secretaria. Essa escolha resultará na facilitação da busca por documentos, pois assim o tempo não será desperdiçado na procura dos mesmos. Na Unidade Escolar analisada a atividade de arquivamento não seguiu esse padrão por anos. Na visita, a Secretária Escolar contou que a maior parte dos documentos se encontram arquivados com um método nada prático, dificultando em muito o trabalho. Desde a fundação da escola foi escolhido um limite de arquivos para o método alfabético, como é possível ver no exemplo abaixo.

\title{
Exemplo 1:
}

\author{
Letra A: de 01 a 2000
}

Letra B: de 2001 a 4000

\section{Letra Z: de $\mathrm{xx}$ a $\mathrm{xx}$}

Arquivando os documentos com esse limite de números criou-se uma organização temporária, pois com o passar do tempo a demanda superou esse limite ocasionando 
um conflito em todo o sistema. Com intuito de melhorar esse processo a Secretária iniciou um projeto de reformulação e modernização da técnica de arquivamento, a partir de 2015 os documentos são arquivados seguindo o exemplo abaixo.

\section{Exemplo 2:}

\section{Letra A: de Al a $\infty$ \\ Letra B: de Bl a $\infty$}

\section{Letra Z: de Zl a $\infty$}

Com a reformulação do método, a busca por documentos posteriores a 2015 ficou muito mais prática e assertiva. A partir do Diagrama de Causa e Efeito do Arquivo Geral, consequentemente o fluxograma foi desenvolvido para a melhor visualização do percurso dos documento dentro da Unidade Escolar e seu arquivamento.

Imagem 3: Fluxograma do percurso dos documentos e do arquivamento 


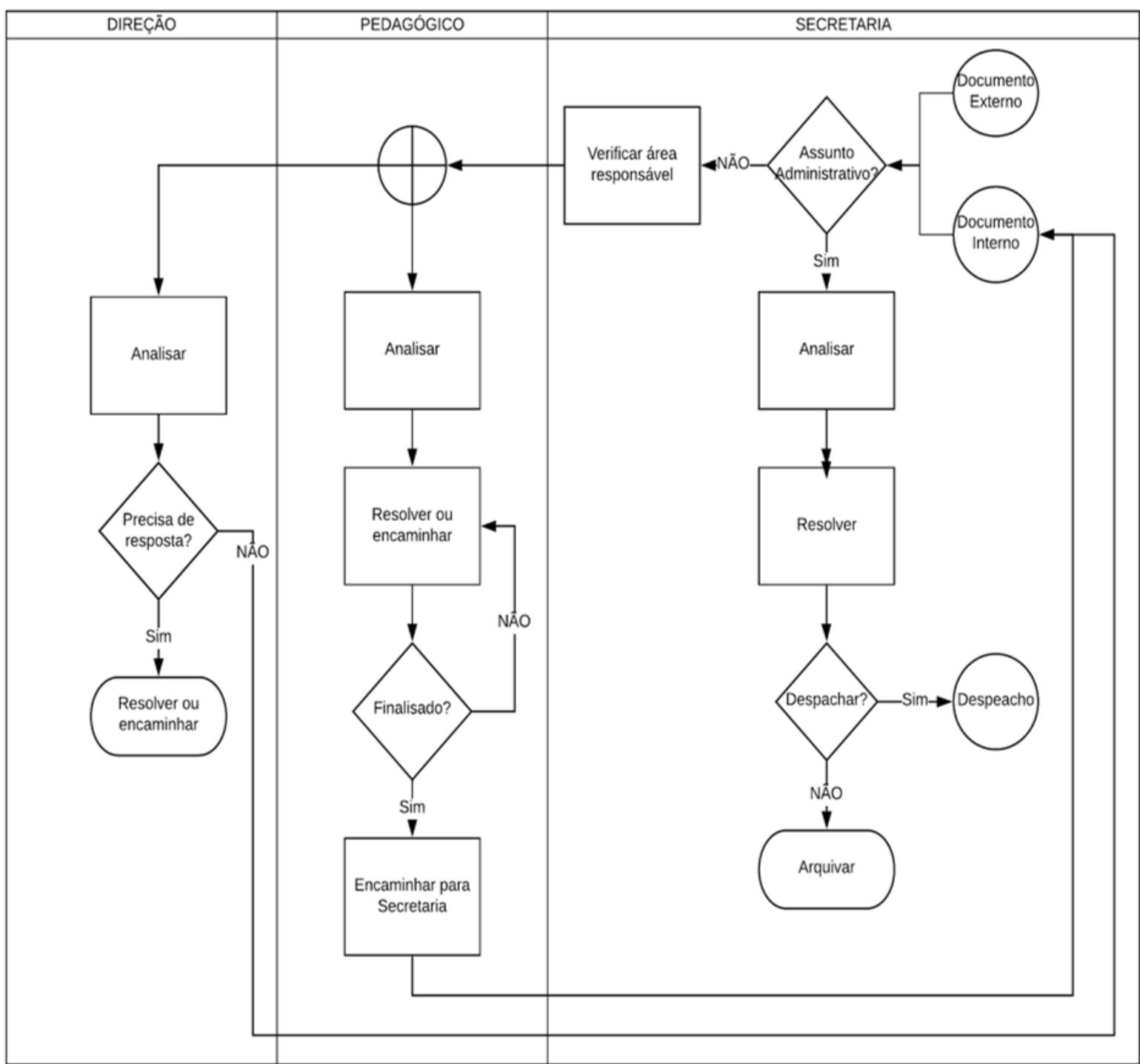

Fonte: Elaborado pelo autor.

Para exemplificar a demanda documental e consequente uso do arquivo, duas situações foram escolhidas, a primeira ocorre quando há uma solicitação de matrícula do aluno na Unidade Escolar.

Imagem 4: llustração do Processo de Matrícula Escolar 


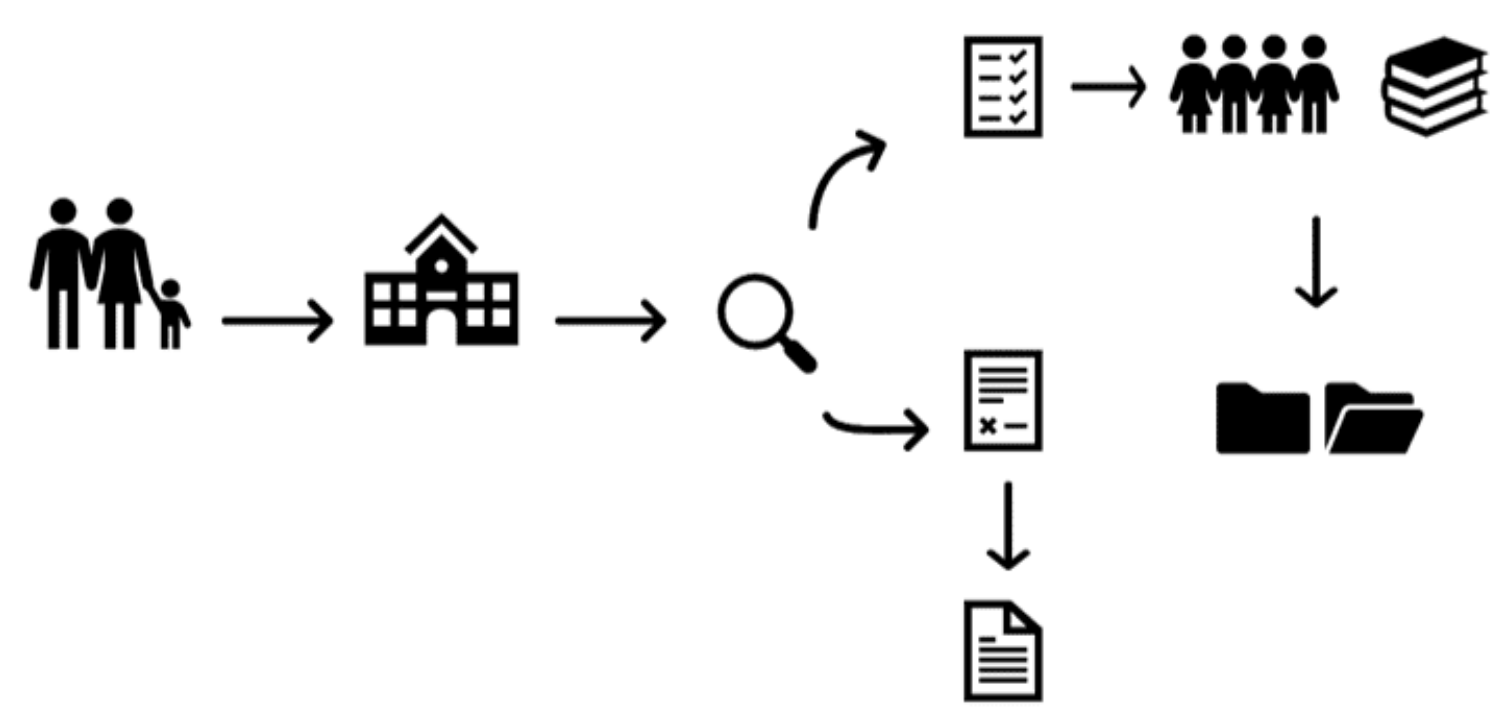

Fonte: Elaborado pelo autor.

Nessa imagem é possível visualizar a solicitação dos responsáveis para matricular o estudante, a escola verifica a documentação necessária e se estiver tudo correto o aluno é matriculado e está apto para iniciar as atividades escolares. A partir desse momento os documentos da vida escolar do estudante são guardados no arquivo da escola. Caso falte algum documento, ou tenha ocorrido algum problema na efetivação da matrícula, a Escola informa aos responsáveis ou encaminha para o setor que administra os casos especiais.

$\mathrm{Na}$ segunda situação pode-se observar na imagem abaixo uma solicitação do Certificado de Formação do estudante.

Imagem 5: llustração do Processo de Certificação Estudantil 

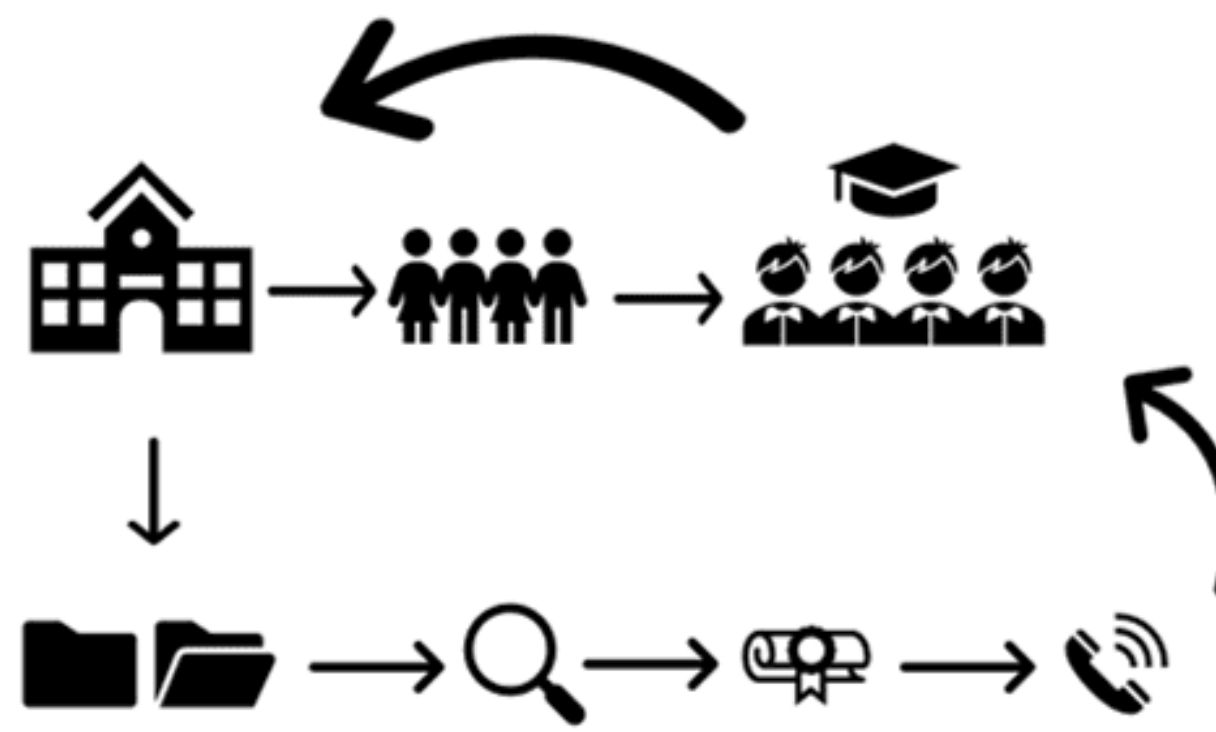

Fonte: Elaborado pelo autor.

Com as informações expostas anteriormente, conclui-se que o Arquivo Geral é atualizado com dados de aproximadamente 600 alunos (capacidade máxima) por ano em época de matrícula escolar. Supondo que esse valor tenha se mantido desde a criação da Escola, a instituição contaria com documentos de aproximadamente de 47400 pessoas em sua posse, se nunca ocorresse nenhuma perda documental. Entretanto, considerando possíveis perdas documentais e supondo nenhuma digitalização de documentos no período entre os anos de 1960 - 2009, o Arquivo Permanente deve conter informações de 29400 pessoas em aproximadamente 784 registros de turmas (de 37,5 pessoas para 16 turmas anuais). Isso não considerando o sistema híbrido de documentação do período entre os anos de $2010^{[6]}-2019$, as informações de aproximadamente 5400 alunos devem estar contidas em 144 registros de turmas (de 37,5 pessoas para 16 turmas anuais) onde aproximadamente $70 \%$ devem ser armazenadas em formato digital e 30\% deve ainda estar armazenado em papéis. Isso significa que só em registros de turmas anuais existem aproximadamente 827,2 documentos esperando para ser reclassificados e digitalizados.Anualmente a escola observa os alunos que concluíram o ciclo acadêmico para efetuar os documentos finais. Para elaborar o Certificado a Unidade Escolar terá que resgatar do arquivo todos os documentos da vida escolar do aluno, verificar se ele está apto a 
receber o documento e em seguida comunicar aos responsáveis quando estiver pronto.

Agora considerando a Certificação estudantil, supondo a capacidade máxima de alunos e 16 turmas anuais com 37,5 alunos cada. Onde no final do ano há sempre uma turma certificada, a instituição deve produzir certificados de 150 alunos/ano resgatando dados dos 4 anos do estudante na instituição. Esses diplomas e históricos escolares devem ser produzidos com agilidade, pois os estudantes serão encaminhados ao ensino médio. Em tese, não há problema com a certificação, pois a mesma é um processo padrão para uma instituição escolar. O problema se encontra ao certificar um dos estudantes presentes dentro dos aproximadamente 827,2 registros de turmas que se encontram no arquivo intermediário e permanente da instituição.

\section{CONSIDERAÇÕES FINAIS}

Existe a necessidade de entender como as práticas administrativas impactam a gestão de arquivos e documentos, todos os atos administrativos deixam uma história, que se apresenta na forma de um fluxo de documentos. As instituições de ensino possuem a peculiaridade de marcar a vida de um indivíduo, localidade e nação. É comum lembrar-se de antigos professores e demais funcionários, recordar como foi o local e a formação educacional. Diferentemente de quando as pessoas vão adquirir seus documentos civis (identidade, CPF, título de eleitor e outros), quase não há recordação. Isso ocorre porque há constância e frequência nesse tipo de serviço.

Esse fato destaca a importância da gestão escolar e do desenvolvimento de boas práticas de gestão de pessoas. A educação tem poder transformar uma sociedade, sendo assim, as instituições de ensino não influem somente em funcionários e no atendimento ao público, elas atuam na comunidade que as cerca e no futuro de uma nação.

O costume da população brasileira de não relembrar o passado de instituições e seus fatos históricos, precariza ou dificulta uma gestão de arquivos e documentos de alta 
eficiência, é notório que diversas instituições públicas possuem problemas com gestão de arquivos pela quantidade de documentos, problemas estruturais ou ambientais. Pois como já citado anteriormente, os recursos são escassos e por isso são alocados em áreas consideradas de maior importância.

A tomada de decisão e o processo de aprendizado organizacional passam pela análise de documentos, tanto que com o processo de digitalização de Arquivos há movimentos para dar mais segurança aos dados, documentos e acervos digitais. Em relação à escola isso é demonstrado nas mudanças de critério nos boletins escolares ao longo do tempo. As instituições de ensino também poderiam aprender com a análise de seus arquivos, uma vez que a instituição passa por diferentes gestores.

Para essa averiguação há necessidade de digitalização do arquivo permanente e intermediário, não só porque favorece a diminuição de retrabalho, erro humano e melhora do atendimento ao público. Como também melhora a tomada de decisão e diminui a incerteza das políticas organizacionais, algo que todo órgão público possui. É fato que as instituições públicas de ensino precisam de melhorias em suas estruturas, entretanto elas também necessitam desenvolver um elevado planejamento estratégico. Para que assim tenham certa autonomia sobre situações inusitadas que ocorrem com passar do tempo.

O ano de 2020, por exemplo, ficará marcado por uma Pandemia mundial[7] uma doença que ataca principalmente o trato respiratório, exigindo adequação para um distanciamento social. A situação da Pandemia em decorrência do COVID-19 ocasionou, consequências para toda a sociedade, não apenas nacional, como também mundial. Essa crise de saúde pública exigiu mudanças imediatas, a fim de amenizar a perda de empregos. As medidas adotadas pela maioria das empresas envolveram a utilização das ferramentas tecnológicas. As instituições mais modernas se adaptaram com mais facilidade e tranquilidade por já estarem habituadas com a sua utilização, entretanto as mais tradicionais consequentemente desempenharam mais esforços para a devida adequação. 
Esse ocorrido é um exemplo real da diversidade de fatores que a Administração Pública pode enfrentar. A educação é fundamental para o crescimento da nação, influenciando diretamente no desempenho de profissionais que futuramente contribuirão para o país. Deste modo, a imersão tecnológica das escolas públicas do Brasil não se trata de investimentos supérfluos, mas sim da concretização de estratégias que capacitam as unidades escolares a passarem por situações críticas como o ocorrido em 2020.

Essa situação provavelmente compromete a reforma da sala de arquivos, visto que os recursos poderão ser redirecionados para outras áreas consideradas mais importantes. Sem a reforma a situação do arquivo pode agravar, como perdas documentais ou o aumento do mesmo. Já que devido diminuição de renda é esperado que a escola pública, venha receber alunos oriundos do ensino privado além da sua população habitual. Porquanto caso não haja apoio administrativo suficiente para cadastrar esses novos alunos de maneira eficaz no sistema digital da prefeitura. Haverá um aumento desnecessário no arquivo permanente e intermediário da instituição, porque para preencher uma vaga cada aluno utiliza vários documentos para tomar posse da mesma.

Abordando novamente a temática de digitalização dos documentos, percebe-se que tanto em situações normais, quanto de crise, essa gestão é essencial para dar mais dinâmica aos processos internos das escolas. Deste modo, políticas devem ser adotadas e incentivadas para que todas as unidades escolares superem os desafios da ausência de profissionais capacitados e de recursos, para assim iniciarem a gestão da digitalização dos documentos.

Em suma, é aconselhável que a instituição que aqui é analisada monte um planejamento com foco em resultado que almeja digitalizar todo o seu Arquivo e padronize um novo sistema de arquivamento, como demonstrado no Exemplo 2, pois com isso garantirá mais rapidez e seriedade nos fluxos documentais e na gestão escolar.

\section{REFERÊNCIAS}


AMARAL, Ivan Luiz Martins Franco do; NUNES, Everardo Duarte. OS CONCEITOS DE GESTÃO E ADMINISTRAÇÃO: APLICAÇÃO AO ESTUDO DAS GESTÕES DOS DIRETORES DA FACULDADE DE CIÊNCIAS MÉDICAS DA UNIVERSIDADE ESTADUAL DE CAMPINAS. Universidade Estadual de Campinas, Brasil. Revista Gestão e Avaliação Universidade Federal de Santa Maria. v. 6 n., p. 67-81. 13 Set./dez. 2017. Disponível em: <https://periodicos.ufsm.br/regae/article/view/28092> Acesso em: 23/09/2019.

BRASIL. LEI No 8.159, DE 8 DE JANEIRO DE 1991. Disponível em: <http://www.planalto.gov.br/ccivil_03/Leis/L8159.htm>. Acesso em: 23/09/2019.

CAMARGO, Denise de. Psicologia Organizacional, 2. ed. reimp. Florianópolis: Departamento de Ciências da Administração - Universidade Federal de Santa Catarina - UFSC, 2012, 124p.

MICHAELIS. Administração. Dicionário Brasileiro da Língua Portuguesa. Disponível em: $\quad$ <https://michaelis.uol.com.br/moderno-portugues/busca/portuguesbrasileiro/administra\%C3\%A7\%C3\%A3o/>. Acesso em: 22/09/2019.

MICHAELIS. Gestão. Dicionário Brasileiro da Língua Portuguesa. Disponível em: $<$ https://michaelis.uol.com.br/moderno-portugues/busca/portuguesbrasileiro/gest\%C3\%A3o/>. Acesso em: 23/09/2019.

NOTÍCIAS UOL. CORONAVÍRUS: OMS declara pandemia. Disponível em: <https://noticias.uol.com.br/ultimas-noticias/bbc/2020/03/11/coronavirus-omsdeclara-pandemia.htm>. Acesso em: 19/06/2020.

O QUE SÃO OS 6M no diagrama de causa e efeito. Radar de Projetos. Disponível em: <http://www.radardeprojetos.com.br/2015/10/o-que-sao-os-6m-no-diagrama-decausa-e.htm>. Acesso em: 27/04/2020.

PAES, Marilena Leite. Arquivo: Teoria e Prática. 3. ed. rev. ampl. Rio de Janeiro: Editora Fundação Getúlio Vargas, 228p., 2004. Disponível em: 
<https://www.academia.edu/30918059/Marilena_Leite_Paes_Arquivo_Teoria_e_pr\% C3\%A1tica>. Acesso em: 27/04/2020.

PETENATE, Ademir J.et al. Ferramentas da qualidade: uma abordagem prática para reduzir custos e defeitos em sua organização. São Paulo: EDIT Projetos, 2012.

PREFEITURA LANÇA o Boletim Escolar Online. EXTRA. Disponível em: $<$ https://extra.globo.com/noticias/rio/prefeitura-lanca-boletim-escolar-online198968.html>. Acesso em: 30/04/2020.

RIO DE JANEIRO. Unidades por atendimento. Jul. 2019. Rio Prefeitura. Secretaria Municipal de Educação - SME. Educação em Números. Disponível em: <http://www.rio.rj.gov.br/web/sme/educacao-em-numeros>. Acesso em: 22/09/2019.

SIGNIFICADO de Documento. Dicio, Dicionário Online de Português. Disponível em: <https://www.dicio.com.br/documento/>. Acesso em: 23/09/2019.

WERLE, Flávia Obino Corrêa. Documentos escolares: impactos das novas tecnologia. História da Educação, v. 6, n. 11, p. 77-96, 2002. Disponível em: <https://seer.ufrgs.br/asphe/article/view/30600>. Acesso em: 23/04/2020.

\author{
ANEXO 1 - CRONOGRAMA COM DETALHAMENTO DE ATIVIDADES \\ Quadro 1: Cronograma de Atividades
}




\begin{tabular}{|c|l|}
\hline \multicolumn{2}{|c|}{ CRONOGRAMA DE ATIVIDADES } \\
\cline { 1 - 2 } SETEMBRO & \multicolumn{1}{|c|}{ DESCRIÇÃo } \\
\cline { 1 - 2 } DIA & \multicolumn{1}{|c|}{$\begin{array}{l}\text { I Entrevista com a secretária: Dados gerais (anos da escola, espaço } \\
\text { físico, estrutura da organização, controle de documentos). }\end{array}$} \\
\cline { 1 - 2 } 11 & $\begin{array}{l}\text { II Entrevista com a Secretária: Curiosidades (arquivo morto); } \\
\text { Entrevista com o Diretor Geral: Informações gerais (funções e } \\
\text { responsabilidades). }\end{array}$ \\
\hline 13 & $\begin{array}{l}\text { III Entrevista com a Secretária: Informações especificas (Atas); } \\
\text { Entrevista com a Diretora Adjunta: Informações gerais (funções, } \\
\text { responsabilidades, experiências, desafios, etc). }\end{array}$ \\
\hline 18 & $\begin{array}{l}\text { IV Entrevista com a Secretária: Informações específicas (visita ao } \\
\text { arquivo e esclarecimento de últimas dúvidas); } \\
\text { Entrevista com a Coordenadora Pedagógica: Informações gerais } \\
\text { (funções e responsabilidades). }\end{array}$ \\
\hline
\end{tabular}

Fonte: Elaborado pelo autor.

\section{APÊNDECE DE RODAPÉ}

[4] Informação da Secretaria Municipal de Educação - SME, Educação em Números, Unidades por tipo de atendimento.

[5] A Teoria de Herzberg (CAMARGO, 2012) basicamente afirma que existem dois fatores que orientam o comportamento humano no trabalho, são os Fatores Higiênicos (extrínsecos) e Fatores Motivacionais (intrínsecos). Onde os higiênicos seriam fatores controláveis da Organização e os motivacionais seriam de fatores controláveis do próprio indivíduo.

[6] Ano do lançamento do Boletim Escolar Online pela Prefeitura da Cidade do Rio de Janeiro.

[7] A Organização Mundial de Saúde (OMS) declarou pandemia de COVID-19. A informação foi confirmada pelo diretor-geral da OMS, Tedros Adhanom Ghebreyesus.

Envaido: Outubro, 2020.

Aprovado: Novembro, 2020. 
